\title{
TENOFOVIR INDUCED HEPATITIS
}

\author{
Hemant R. Gupta1 ${ }^{1}$ Nishi Vishwanathan², Utina Kichu3 ${ }^{3}$, Minal A. Meshram ${ }^{4}$
}

${ }_{1}^{1}$ Associate Professor and HOI, Department of Medicine, JJ Group of Hospitals and Grant Government Medical College, Mumbai, Maharashtra, India.

2Intern, Department of Medicine, JJ Group of Hospitals and Grant Government Medical College, Mumbai, Maharashtra, India. ${ }^{3}$ Chief Resident, Department of Medicine, JJ Group of Hospitals and Grant Government Medical College, Mumbai, Maharashtra, India. ${ }^{4}$ Chief Resident, Department of Medicine, JJ Group of Hospitals and Grant Government Medical College, Mumbai, Maharashtra, India. HOW TO CITE THIS ARTICLE: Gupta HR, Vishwanathan N, Kichu U, et al. Tenofovir induced hepatitis. J. Evolution Med. Dent. Sci. 2018;7(43):4693-4694, DOI: $10.14260 /$ jemds/2018/1046

\section{PRESENTATION OF CASE}

A 23-year-old sero-positive male on TLE (Tenofovir, Lamivudine, Efavirenz) regimen for 8 months was admitted under medicine care with complaints of yellowish discolouration of eyes and skin, abdominal bloating, nausea and decreased appetite in the last 3 months.

The use of Highly Active Anti-Retroviral Therapy (HAART) for management of HIV seropositive patients has brought about radical enhancement in their lifespan and quality of life. Recognising the side effects and toxicity of long-term use of ART is crucial for their management. Tenofovir is a nucleotide analog reverse-transcriptase inhibitor (NtRTI) and cases of Tenofovir induced hepatitis are rare. However, a majority of NtRTIs can induce mitochondrial damage and therefore have potential for liver damage. Here, we report a rare case of tenofovir causing hepatitis in a patient with none of the recognisable risk factors who is seropositive.

\section{DIFFERENTIAL DIAGNOSES}

- Viral hepatitis including Hepatitis A, Hepatitis B, Hepatitis C, Hepatitis D and Hepatitis E.

- Autoimmune hepatitis.

- Alcoholic hepatitis.

- Medication induced Hepatitis (e.g. Tenofovir induced hepatitis).

- Leptospirosis.

- Liver abscess.

\section{CLINICAL DIAGNOSIS}

On general examination patient was conscious, orientated to time, place and person; pulse $84 / \mathrm{min}$, blood pressure $110 / 70$ $\mathrm{mmHg}$ in right upper arm in supine position, respiratory rate $18 / \mathrm{min}$. Initially, the patient was treated as a case of jaundice under evaluation in a seropositive patient. There were no signs of liver cell failure. Systemic examination was unremarkable, except right upper quadrant tenderness.

\section{PATHOLOGICAL DISCUSSION}

Liver toxicity is one of the most relevant adverse effects of ART, owing to its frequency and the fact that it can lead to interruption of therapy, clinical hepatitis and death.(1-3)

'Financial or Other Competing Interest': None.

Submission 03-09-2018, Peer Review 05-10-2018,

Acceptance 12-10-2018, Published 22-10-2018.

Corresponding Author:

Nishi Vishwanathan,

A/18, Divine Light Soc., Andheri-Kurla Road,

Andheri East, Mumbai-400093, Maharashtra, India.

E-mail: nishiv1995@gmail.com

DOI: $10.14260 /$ jemds/2018/1046

\section{(c) $(1)$}

It is well known that any antiretroviral drug can produce liver toxicity.

Tenofovir is an NtRTI. It selectively inhibits viral reverse transcriptase, a crucial enzyme in retroviruses such as Human Immunodeficiency Virus (HIV), while showing limited inhibition of DNA polymerase $\alpha, \beta$ and mitochondrial DNA polymerase $\gamma$ which are human enzymes. The drug Tenofovir lacks an important hydroxyl group, which prevents the formation of a $5^{\prime}$ to $3^{\prime}$ phosphodiester linkage. This linkage is needed for elongation of the DNA chain. Once Tenofovir gets incorporated, it causes premature termination of DNA transcription. This prevents viral replication. Inhibition of mitochondrial DNA polymerase $\gamma$ by NtRTI is hypothesised to cause hepatitis. Mitochondrial toxicity is an infrequent but a distinctive type of hepatotoxicity that may evolve to acute liver failure. Mitochondrial toxicity can lead to a variety of manifestations such as lactic acidosis, hepatitis, myopathy, nephrotoxicity, pancreatitis and peripheral neuropathy. ${ }^{(3,4)}$ The relative potential of inhibition of mitochondrial DNA polymerase gamma in cell cultures have been postulated as zalcitabine $>$ didanosine $>$ stavudine $>$ lamivudine $>$ zidovudine $>$ abacavir.(4) In vitro data support an additive or synergistic long-term mitochondrial toxicity with some NtRTI combinations. Hydroxyurea, used as coadjuvant treatment, seems to increase the toxic effect of some NtRTI due to the rise of intracellular levels of 50 triphosphates products. In all the reported cases, patients had some or the other underlying factor or some risk factor predisposing to mitochondrial toxicity. Pre-existing Hepatitis $\mathrm{B}$ or Hepatitis C infection tends to predispose towards hepatitis. In the case reported by Murphy et al the predisposing factor was pre-existing renal insufficiency, coadministration of Didanosine which has high affinity for mitochondrial DNA polymerase and use of diuretics.(5) In another case reported by Hashim et al, there was underlying HCV infection, E. coli bacteraemia and hypotensive episodes.(6) Contrary to this in the present case, none of the identifiable risk factors were present and patient's baseline investigations were all normal.

\section{DISCUSSION OF MANAGEMENT}

On general examination, vital parameters were normal and on systemic examination no significant abnormality was found. Investigations showed severe anaemia with haemoglobin $13.6 \mathrm{gm} / \mathrm{dL}$. Total leucocyte count 12,000 cells/dL, platelet count of 497,000/dL. In liver function test, aspartate transaminase was $414 \mathrm{IU} / \mathrm{L}$, alanine transaminase $296 \mathrm{IU} / \mathrm{L}$ and total bilirubin $5.7 \mathrm{mg} / \mathrm{dL}$. In renal function test, serum urea was $18 \mathrm{mg} / \mathrm{dL}$ and serum creatinine $0.7 \mathrm{mg} / \mathrm{dL}$. Serum sodium was $141 \mathrm{mEq} / \mathrm{L}$ and serum potassium was 3.6 $\mathrm{mEq} / \mathrm{L}$. Serum amylase was $125 \mathrm{IU} / \mathrm{L}$ and serum lipase was 
136 IU/L. Patient was on ART regimen of TLE (Tenofovir, Lamivudine, Efavirenz) for 8 months.

CD4 count was 814 . Viral markers were negative for all known causes of hepatitis including Hepatitis A, Hepatitis B, Hepatitis C, Hepatitis D and Hepatitis E. There were no signs of alcoholic or autoimmune hepatitis. Infections affecting the liver like Leptospirosis were also ruled out.

\section{FINAL DIAGNOSIS}

Diagnosis of Tenofovir induced hepatitis was made. Tenofovir was stopped immediately and the patient was kept under close observation. The liver function test showed a drastic improvement within next few days after stopping TLE regimen and supportive treatment. The three main considerations necessary for the management of transaminase elevation after the introduction of HAART (Highly Active Antiretroviral Therapy) are severity, clinical impact and aetiologic mechanisms. The presence of liver decompensation is one of the reasons to stop treatment. To conclude, though rare, Tenofovir can cause severe hepatitis in a patient with all normal parameters. (7) Clinicians should keep these identified adverse effects in mind and look for the warning signs in patients on ART, especially when it comes to a TLE regimen containing Tenofovir.

\section{REFERENCES}

[1] Boubaker K, Flepp M, Sudre P, et al. Hyperlactatemia and antiretroviral therapy: the Swiss HIV Cohort Study. Clin Infect Dis 2001;33(11):1931-7.
[2] Aberg JA, Kaplan JE, Libman H, et al. Primary care guidelines for the management of persons infected with human immunodeficiency virus: 2009 update by the HIV medicine Association of the Infectious Diseases Society of America. Clin Infect Dis 2009;49(5):651-81.

[3] Schambelan M, Benson CA, Carr A, et al. Management of metabolic complications associated with antiretroviral therapy for HIV-1 infection: recommendations of an International AIDS SocietyUSA panel. J Acquir Immune Defic Syndr 2002;31(3):257-75.

[4] Kakuda TN. Pharmacology of nucleoside and nucleotide reverse transcriptase inhibitor-induced mitochondrial toxicity. Clin Ther 2000;22(6):685-708.

[5] Murphy MD, O'Hearn M, Chou S. Fatal lactic acidosis and acute renal failure after addition of tenofovir to an antiretroviral regimen containing didanosine. Clin Infect Dis 2003;36(8):1082-5.

[6] Hashim H, Sahari NS, Lim SSM, et al. Fatal tenofovirassociateacd lactic acidosis: a case report. Iran Red Crescent Med J 2015;17(10):e19546.

[7] Chhatwani CM, Purohit JB, Vakil AP, et al. Tenofovir induced severe lactic acidosis and hepatitis. National Journal of Medical Research 2016;6(3):288-9. 